\title{
DESAIN DAN PEMASANGAN RUMAH IKAN SEBAGAI ALTERNATIF PENINGKATAN HASIL TANGKAPAN DI SENDANGBIRU KABUPATEN MALANG
}

\author{
Aida Sartimbul, Feni Iranawati) \\ ${ }^{1}$ Fakultas Perikanan dan Ilmu Kelautan, Universitas Brawijaya \\ aida@ub.ac.id \\ fe_iranawati@ub.ac.id
}

\begin{abstract}
ABSTRAK
The objective of community service project activity is produce fish housing to be owned by local fishermen. This device will be jointly managed and supervised by fisherman membership-based community known as Mina Rukun and Duyung Maju. This activity was performed in order to increase the fishermen involvement and community engagement to produce environmentally friendly collecting fish tool known as fish housing. The program was implemented in several stages, the first stage is the agreement confirmation with the fishermen community targeted, the second stage is open sea survey area to find the potential location for the fish housing, the third is the design manufacture and installation of fish housing and the last is the workshop for the fishermen to give information on how to make logbook for their fishing capture that will be beneficial for future management. The program was conducted over seven months i.e. from April - November 2017.
\end{abstract}

\section{PENDAHULUAN}

Perikanan pancing ulur dengan armada jukung marak hadir di perairan Sendangbiru, Kabupaten Malang dalam kurun waktu 10 (sepuluh) tahun terakhir. Hal tersebut mampu meningkatkan aktivitas perikanan laut di wilayah pantai selatan sepanjang 85,92 $\mathrm{km}$ dimana potensi perikanan mencapai 80.435 ton per tahun. Potensi perikanan yang cukup besar ini didukung dengan berkembangnya beberapa fasilitas kepelabuhanan seperti: Pusat Pendaratan Ikan (PPI) Pondokdadap di Kecamatan Sumbermanjing Wetan, Tempat Pelelangan Ikan (TPI) Licin di Kecamatan Ampelgading dan TPI Sipelot di Kecamatan Tirtoyudo (Harlyan et al., 2015).

Perkembangan alat tangkap pancing ulur dari tahun ke tahun berdampak pada peningkatan pemanfaatan rumah ikan (rumpon) sebagai alat bantu penangkapan. Keberadaan rumah ikan dimanfaatkan nelayan untuk mencari gerombolan ikan target tangkapan. Dengan adanya rumah ikan maka ikan akan terkonsentrasi di rumah ikan yang lokasinya telah diketahui sebelumnya sehingga akan menimalisasi biaya operasional sekaligus meningkatkan hasil tangkapan. Menurut Simbolon et al. (2013), efektivitas alat tangkap akan meningkat sebesar 90,53\% dengan pemanfaatan rumah ikan.

Kondisi kepemilikan rumah ikan di perairan Sendangbiru dikelola secara mandiri oleh masing-masing kelompok nelayan, dimana dalam satu kelompok nelayan terdiri dari 10-20 orang. Tiap kelompok nelayan memanfaatkan satu unit rumah ikan. Dengan semakin meningkatnya jumlah nelayan pancing ulur, menyebabkan jumlah unit rumah ikan tersebut cenderung tidak sebanding dengan jumlah nelayan yang memanfaatkannya. Sebagai gambaran dan perbandingan, di perairan Selatan Jawa yang lain (Perairan Pacitan), satu unit rumpon atau rumah ikan yang dimanfaatkan secara berkelompok oleh 4-5 unit alat tangkap pancing tonda (Nurani et al., 2014).

Pengelolaan rumah ikan di wilayah perairan Sendangbiru yang umumnya dilakukan secara mandiri maka tidak 
jarang nelayan setempat memanfaatkan rumah ikan tanpa melakukan pelaporan posisi rumah ikannya kepada Dinas Perikanan dan Kelautan Kabupaten Malang. Kondisi semacam ini melahirkan konflik kepentingan antar nelayan yang sulit diselesaikan dan ditambah lagi dengan jumlah kelompok nelayan pancing ulur yang meningkat dalam kurun waktu lima tahun terakhir. Kelompok-kelompok nelayan baru merasa bahwa jumlah rumah ikan yang mereka miliki tidak sebanding dengan jumlah nelayan dalam satu kelompok yang memanfaatkan rumah ikan tersebut. Akar permasalahan dari kondisi ini adalah terbatasnya jumlah rumah ikan yang dimiliki oleh masing-masing kelompok nelayan.

Kelompok Nelayan Mina Rukun dan Dayung Maju merupakan bagian dari kelompok nelayan baru yang berharap adanya bantuan sebagai sarana pengumpul ikan sehingga nantinya mampu meningkatkan hasil tangkapan yang mereka peroleh. Jika ditinjau dari aspek lingkungannya, rumpon yang umumnya dioperasikan di perairan tersebut berbahan dasar styrofoam yang digunakan sebagai pelampung. Berdasarkan hasil penelitian Sari et al. (2014), bahan tersebut merupakan bahan yang berbahaya bagi lingkungan karena sulit terurai. Disamping itu jika ditinjau dari segi teknis, berdasarkan wawancara dari nelayan setempat, bahan styrofoam pada rumah ikan hanya memiliki umur teknis yang cukup singkat (tiga tahun).

Berdasarkan fakta-fakta tersebut, lewat kegiatan pengabdian kepada masyarakat ini dilakukan pembuatan rumah ikan oleh masyarakat setempat dengan menggunakan bahan yang lebih ramah lingkungan dan memiliki umur teknis yang jauh lebih panjang yaitu tali polypropylene (PP). Rumah ikan sendiri merupakan alat bantu pengumpul ikan yang memiliki fungsi untuk mengkonsentrasikan ikan sehingga akan mempermudah kegiatan operasional alat tangkap pancing ulur. Disamping itu, alat ini memiliki fungsi ekologis sebagai tempat telur, larva dan juvenile ikan untuk tumbuh dan berkembang biak.
Rancangan kegiatan pembuatan dan pengoperasian rumah ikan ini melibatkan masyarakat setempat sehingga terbentuk rasa kepemilikan atas rumah ikan tersebut. Pemanfaatan hasil pengoperasian rumah ikan juga melibatkan peran Kelompok Pengawas Masyarakat (Pokwasmas) yang anggotanya adalah nelayan dan masyarakat setempat, sehingga diharapkan mampu meminimalisasi konflik-konflik yang terjadi.

Manfaat lain yang akan diperoleh nelayan setempat adalah aplikasi rumah ikan ramah lingkungan berbasis masyarakat ini akan menambah jumlah alat pengumpul ikan yang dikelola oleh nelayan lokal, dalam hal ini adalah Kelompok Nelayan Mina Rukun dan Dayung Maju dengan tetap melalui kontrol pemerintah daerah setempat dan Pokwasmas (Kelompok Pengawas Masyarakat). Secara ekonomi akan mampu mengembangkan kesejahteraan nelayan pancing ulur dengan meningkatnya produktifitas hasil tangkapan, dan secara institusional akan mampu meminimalisir konflik nelayan dengan adanya kepemilikan bersama atas rumah ikan tersebut.

\section{METODE PENELITIAN}

Kegiatan ini dilaksanakan di Perairan Sendangbiru, Kabupaten Malang, Jawa Timur sepanjang bulan April-November 2017. Tahapan produksi rumah ikan secara sederhana meliputi survei konfirmasi ke kelompok nelayan, pembuatan peta batimetri dan pemilihan lokasi potensial rumah ikan, sampai pelatihan pencatatan hasil tangkapan, monitoring dan evaluasi dapat dijelaskan dengan alur kegiatan pada Gambar 1. 


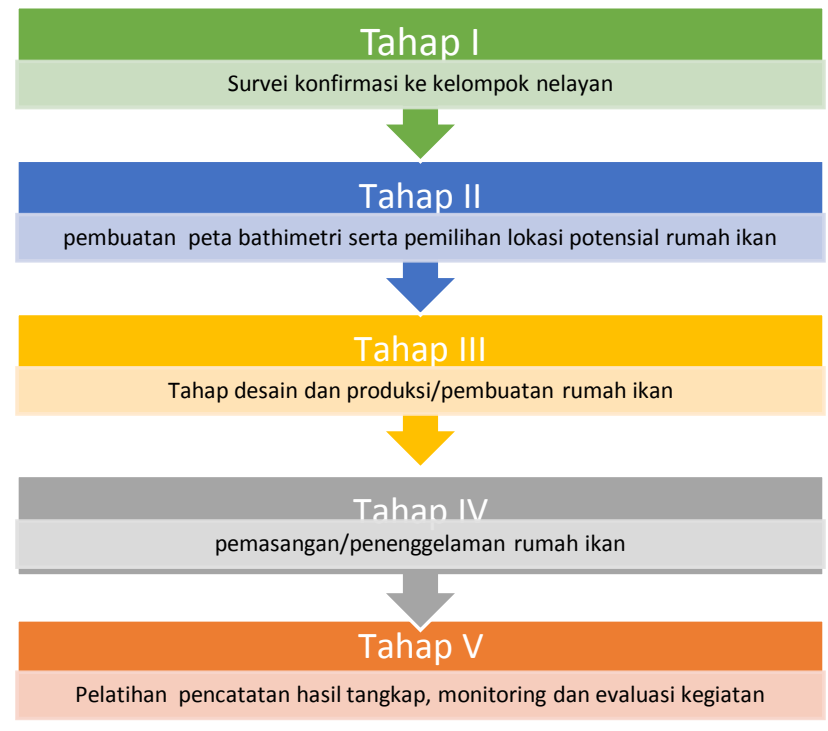

Gambar 1. Alur Kegiatan

\subsection{Survei konfirmasi serta pemilihan lokasi potensial}

Kelompok nelayan mitra yang terdiri dari Kelompok Nelayan Mina Rukun dan Dayung Maju berada di desa Tambakrejo, tidak jauh dari Pelabuhan Pendaratan Ikan (PPI) Pondokdadap, Kabupaten Malang. Kedua kelompok nelayan ini merupakan kelompok nelayan alat tangkap pancing ulur yang baru terbentuk. Pengoperasian alat tangkap pancing ulur sendiri sangat dimudahkan dengan keberadaan alat pengumpul ikan ini, karena dengan begitu nelayan telah mengetahui lokasi daerah penangkapan. Pada survey ini dilakukan koordinasi lebih lanjut dengan mitra kegiatan serta dilakukan penentuan lokasi pemasangan rumah ikan.

\subsection{Produksi Rumah Ikan}

Alat yang digunakan dalam memproduksi rumah ikan adalah cetok, gunting, pisau, pacul, GPS Garmin. Bahan yang digunakan adalah tali plastik polypropylene diameter $22 / 24 \mathrm{~mm}$ ukuran $1500 \mathrm{~m}$, semen cor, daun kelapa, jaring, tali tambang, kawat besi/ beton, ban bekas dan paku.

Pembuatan rumah ikan yang dilakukan dengan membuat ponton dari Styrofoam yang dibungkus dengan terpal, disimpul dengan tali Polyethylene (PE) yang mempunyai sifat lebih lentur dari pada PP, sesuai dengan desain rumah ikan laut dalam. Selain itu dibuatkan juga pemberat yang terbuat dari semen dan kawat beton (beton) pada tiap sisi tali rumah ikan. Pada sisi kiri kanan partisi dirangkaikan dengan lembaran jaring dan daun kelapa sebagai shelter dan attractor-nya.

\subsection{Pemasangan Rumah Ikan}

Pemasangan rumah ikan dilakukan dengan cara menenggelamkan rumah ikan di daerah yang telah dipilih dengan acuan peta batimetri (Gambar 2), pada kedalaman antara 800-1000 m di Lintang 8. Untuk mencapai target posisi pemasangan, rumah ikan dan seluruh perlengkapannya dibawa ke daerah penangkapan ikan dengan menggunakan kapal.

\subsection{Pelatihan dan dan pembinaan Kelompok Nelayan}

Untuk menyiapkan nelayan dalam pengelolaan hasil tangkapan yang berkelanjutan dan untuk masa depan yang lebih baik, maka pada kegiatan pengabdian kepada masyarakat ini juga dilakukan pelatihan kepada nelayan mitra IbM berupa pelatihan pembukuan hasil tangkapan. Kegiatan pelatihan ini dilakukan karena pada saat survei konfirmasi dengan mitra IbM, diketahui bahwa hampir semua anggota nelayan tidak pernah melakukan pencatatan hasil tangkapannya, sehingga tidak dapat diketahui adanya peningkatan hasil tangkap setelah dipasang rumah ikan di daerah penangkapannya. Selain itu, data tersebut sangat diperlukan untuk tujuan monitoring ketersediaan sumberdaya ikan di daerah penangkapan di Malang Selatan.

\subsection{Evaluasi Kegiatan}

Akhir kegiatan pengabdian kepada masyarakat ini adalah monitoring dan evaluasi. Kegiatan monitoring dan evaluasi ini bertujuan untuk memastikan keberadaan rumah ikan yang dipasang tersebut, apakah masih terletak pada posisi semula atau paling tidak ada pada daerah penangkapan yang sudah ditentukan. Selain itu, evaluasi juga diperlukan untuk memastikan fungsi ekologis rumah ikan 
sebagai pengumpul ikan dapat berjalan dengan baik. Kegiatan evaluasi dilakukan dengan cara mengunjungi ke posisi pemasangan dan melakukan wawancara dengan mitra sebagai pengelola.

\section{HASIL DAN PEMBAHASAN}

\subsection{Penentuan Lokasi Rumah Ikan}

Salah satu faktor keberhasilan dalam peletakan rumah ikan adalah pengetahuan tentang kedalaman (batimetri) perairan, sehingga ketersediaan peta batimetri sangat diperlukan dalam menentukan lokasi penempatan rumah ikan yang tepat. Berdasarkan pengalaman dari kelompok nelayan di luar mitra IbM UB, yang kehilangan rumponnya (alat pengumpul ikan) karena telah terjadi kesalahan prediksi lokasi rumpon yang seharusnya diletakkan pada kedalaman $1000 \mathrm{~m}$, namun karena ketidaktahuan tentang kedalamannya, maka rumpon tersebut dilepas pada kedalaman lebih dari $2000 \mathrm{~m}$ dan bertepatan dengan lokasi palung laut Jawa. Sebagai akibatnya rumah ikan tersebut seketika tenggelam dan hilang. Kerugian yang cukup besar diderita oleh nelayan-nelayan tersebut karena kehilangan rumponnya. Untuk mengatisipasi kerugian yang ditimbulkan akibat kesalahan prediksi kedalaman perairan untuk peletakan rumah ikan, maka pada pemasangan rumah ikan di Malang Selatan ini, peneliti telah membuat peta batimetri/ kedalaman dengan menggunakan data yang bersumber dari Gebco (2015) seperti yang disajikan pada Gambar 2.

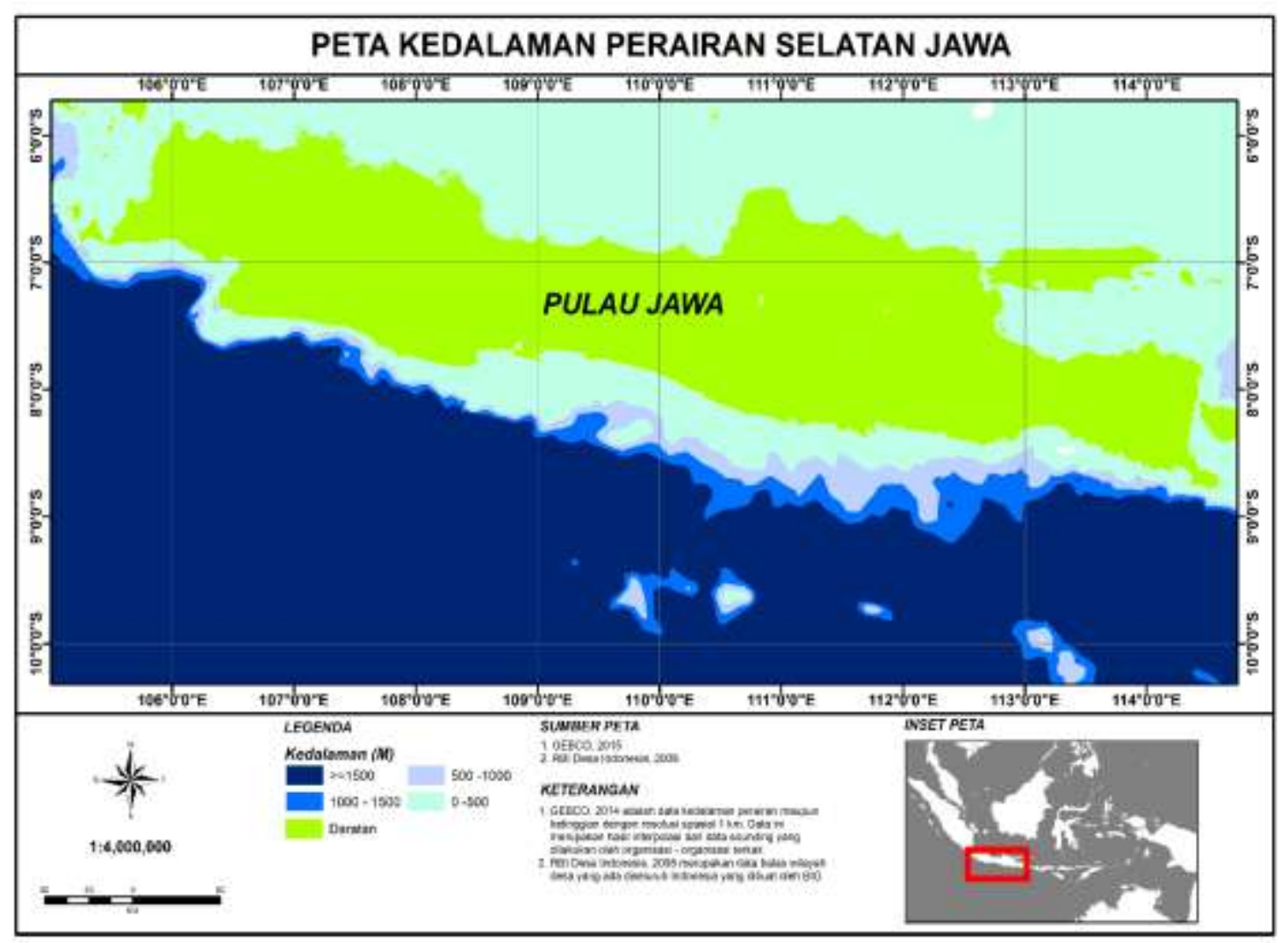

Gambar 2. Peta batimetri/ kedalaman Perairan di Selatan Jawa. Peta ini digunakan sebagai acuan dalam pembuatan dan pelepaskan rumah ikan agar sesuai dengan harapan. 


\subsection{Desain dan Produksi rumah ikan}

Desain rumah ikan untuk laut dalam berbeda dengan rumah ikan yang digunakan di perairan dangkal. Desain rumah ikan yang diaplikasikan pada pengabdian kepada masyarakat ini adalah berupa rangkaian tali PP, pemberat beton, pelampung, jaring dan anyaman rangkaian daun kelapa, seperti tersaji pada Gambar 3. Adapun komponen-komponen rumah ikan secara detail disajikan pada Gambar 4 sampai 6.

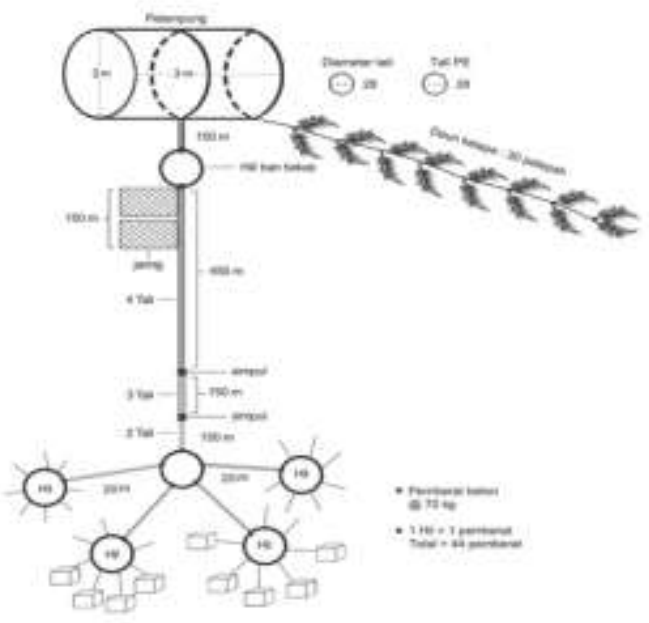

Gambar 3. Desain rumah ikan untuk perairan Sendang Biru

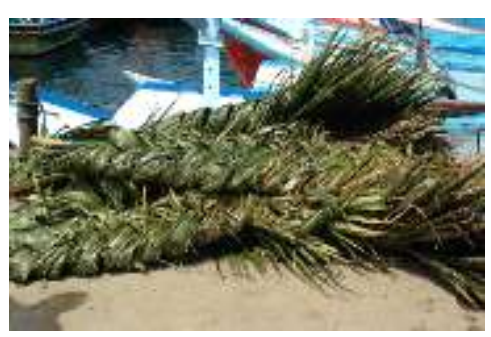

Gambar 4. Attractor dari daun kelapa

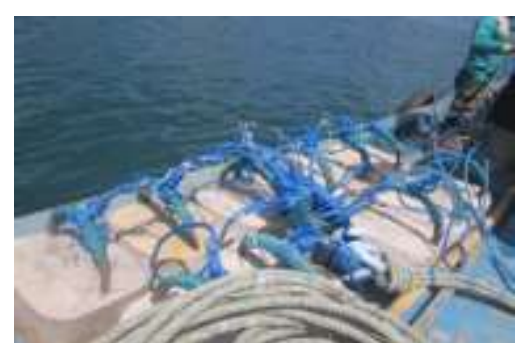

Gambar 5. Rangkaian pemberat semen beton

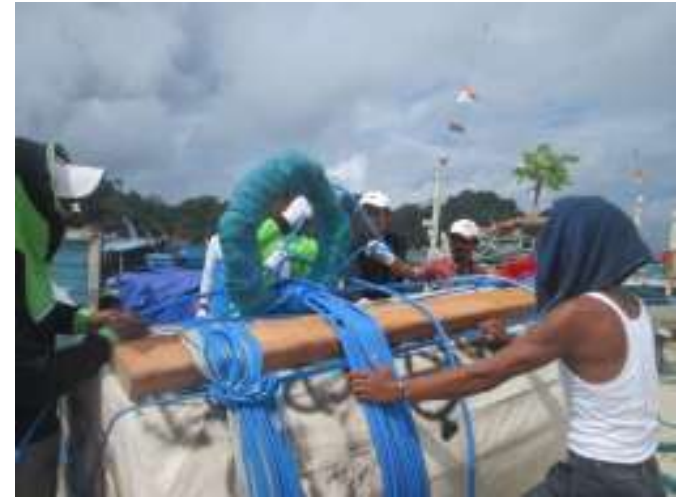

Gambar 6. Ponton/ pelampung rumah ikan

Secara detail, tahapan pembuatan rumah ikan adalah sebagai berikut:

a. Pembuatan pemberat dan pengaitnya

Pemberat dibuat sebanyak 44 buah yang dibagi dalam 4 hill (pengait) yang terbuat dari ban bekas yang dililit dengan tali sebagai penguat. Masing-masing pemberat dibuat dari semen beton dengan berat 70 $\mathrm{kg}$.

b. Pembuatan attractor

Attactor terbuat dari daun kelapa yang di rangkai/ dijalin seperti kepang rambut. Dalam 1 (satu) unit rumah ikan dibuat 1( satu) rangkai attractor yang terdiri dari 30 buah rangkaian jalinan daun kelapa

c. Pembuatan shelter

Shelter terbuat dari jaring dengan lebar 2 meter dan panjang 150 meter

d. Pembuatan ponton

Ponton terbuat dari Styrofoam padat yang dibungkus dengan kain terpal/ kain tahan air agar lebih tahan lama. Ponton berbentuk tabung dengan diameter 2 meter dan panjang 3 meter.

e. Perakitan rumah ikan

Rangka yang terbuat dari tali polypropylene (PP) dengan diameter $24 \mathrm{~mm}$ dirangkaikan dengan ponton, shelter, attractor dan pemberat dengan hill (pengait) yang terbuat dari ban bekas yang dililit tali. Panjang rangka I dari hill pertama dengan ponton adalah $150 \mathrm{~m}$ yang terbuat dari 2 buah lilitan tali PE. Selanjutnya dipasang shelter dari hill pertama pada rangka II yang terbuat dari 4 lilitan tali PE sepanjang $450 \mathrm{~m}$, rangka selanjutnya disimpul dan di rangkai dengan rangka berikutnya (III) yang terbuat dari 3 buah lilitan tali PE dengan panjang $150 \mathrm{~m}$. Selanjutnya dilakukan penyimpulan dan perangkaian 
dengan rangka IV yang terbuat dari 2 lilitan tali PE sepanjang $150 \mathrm{~m}$. Rangka IV akan dikaitan dengan hill ke 2. Hill 2 akan dirangkaian 2 lilitan tali PE sepanjang $150 \mathrm{~m}$ dengan 4 hill pemberat. Masing-masing pemberat dikaitkan dengan 2 lilitan tali PE sepanjang 25m dengan hill pemberat.

Setelah selesai perakitan, hasil akhir rumah ikan siap diletakkan pada kedalaman 800-1000 m disajikan pada Gambar 7.

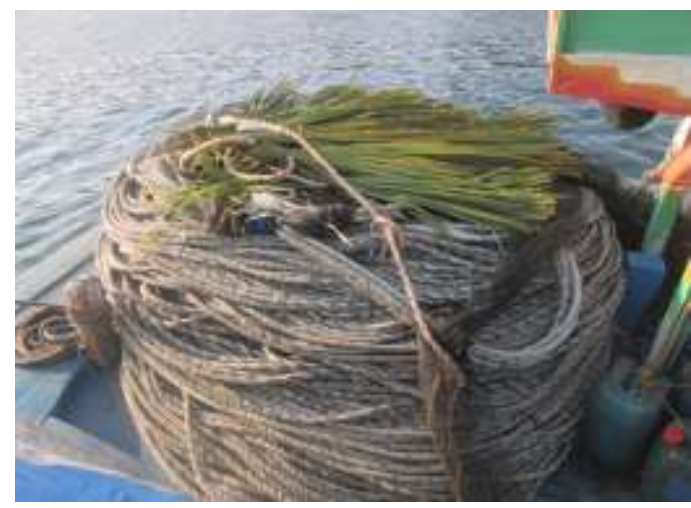

Gambar 7. Rumah Ikan siap dipasang atau ditenggelamkan di lokasi yang sudah ditentukan berdasarkan peta batimetri.

\subsection{Pemasangan Rumah Ikan}

Pemasangan/ penenggelaman rumah ikan dilakukan pada tanggal 11 Agustus 2017. Pemasangan satu unit rumah ikan ini dilakukan dengan oleh nelayan mitra dibantu beberapa mahasiswa Fakultas Perikanan dan Ilmu Kelautan Universitas Brawijaya yang sedang melaksanakan kegiatan Praktek Kerja Magang di Sendangbiru dengan menggunakan 1 (satu) kapal nelayan. Proses pemasangan rumah ikan di Perairan Sendangbiru disajikan pada Gambar 8-11.

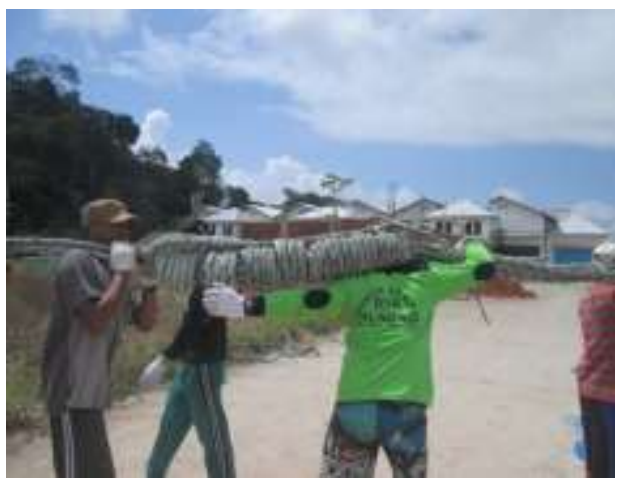

Gambar 8. Proses pengangkutan komponenkomponen Rumah Ikan ke kapal

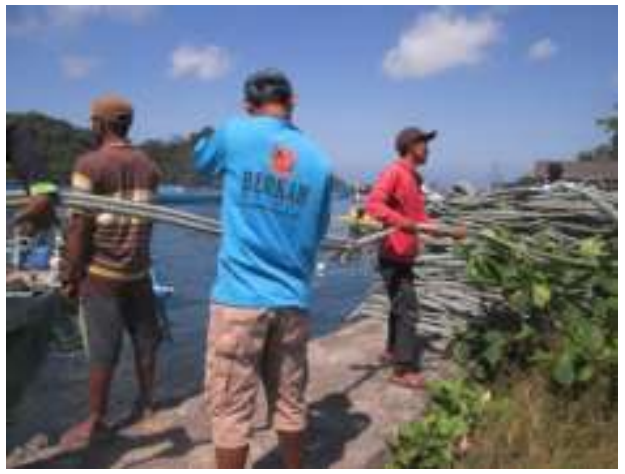

Gambar 9. Loading Rumah Ikan ke kapal

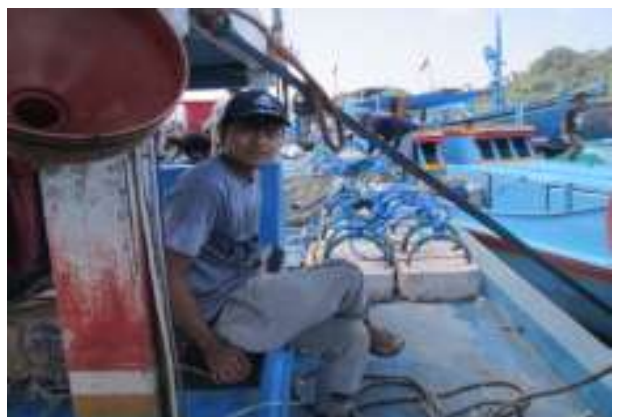

Gambar 10. Menuju ke Lokasi penempatan rumah ikan

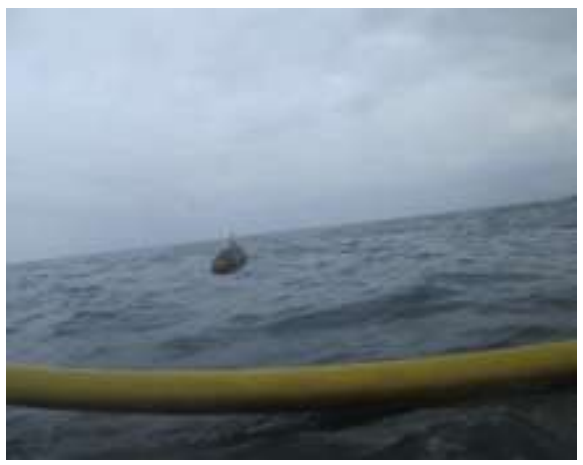

Gambar 11. Rumah Ikan sudah terpasang

\subsection{Kegiatan Pelatihan Pembukuan hasil tangkap}

Setelah dilakukan pemasangan rumah ikan, langkah selanjutnya adalah pelatihan pembukuan hasil tangkapan. Kegiatan pelatihan pembukuan hasil tangkap ini dilakukan pada tanggal 23 September 2017. Target dari pelatihan ini ditujukan pada para istri nelayan untuk membantu mengelola hasil penangkapan dan keuangan. Peserta yang ikut dalam 
kegiatan ini sebanyak 19 orang istri nelayan. Kegiatan ini bertujuan agar setiap nelayan memiliki catatan harian atas hasil tangkapan yang diperoleh. Hal ini sangat diperlukan selain sebagai bentuk menitoring, data ini dapat digunakan untuk menduga berapa banyak sumberdaya ikan yang masih ada dan berapa jumlah tangkapan yang diperblehkan agar sumberdaya ikan tersebut tetap lestari. Kegiatan pelatihan pembukuan disajikan pada Gambar 12.

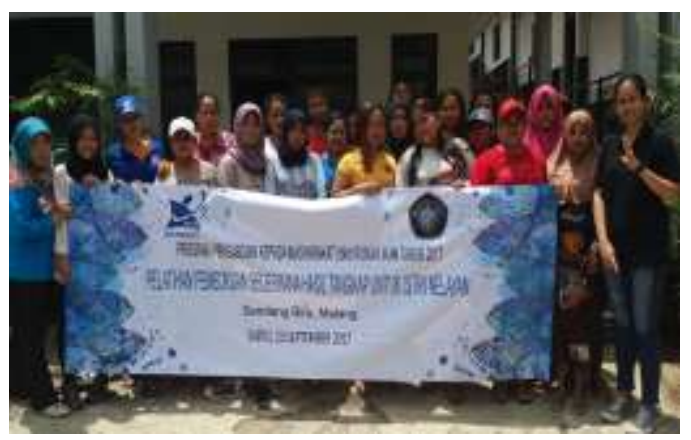

Gambar 12. Kegiatan Pelatihan pembukuan hasil tangkap yang diikuti oleh para istri nelayan.

\subsection{Evaluasi}

Sebagai akhir dari kegiatan pengabdian kepada masyarakat ini adalah kegiatan evaluasi dan monitoring, yang dilaksanakan pada tanggal 21 Oktober 2017. Kegiatan ini bertujuan untuk memonitor dan melihat perkembangan hasil tangkapan setelah terpasang rumah ikan di Perairan Sendangbiru. Monitoring dilakukan tiap bulan sekali setelah setelah pemasangan, namun penangkapan berdampak setelah 3 bulan pemasangan (Nopember 2017). Ketika artikel ini disusun belum genap 3 (tiga) bulan, untuk melihat peningkatan hasil tangkapan. Namun demikian, monitoring tetap dilaksanakan untuk memastikan bahwa rumah ikan masih terletak pada posisi yang sama. Pada kegiatan evaluasi tersebut dilakukan pula konfirmasi kegiatan rutin yang memanfaatkan rumah ikan kepada nelayan Mina Rukun dan Dayung Maju. Konfirmasi juga dilakukan kepada Ketua Pokmaswas dan pihak terkait seperti staf penangkapan Dinas Perikanan dan Kelautan Kabupaten Malang.

\section{KESIMPULAN DAN SARAN}

Kegiatan pengabdian kepada masyarakat ini telah berhasil dibuat dan dipasang 1 (satu) unit rumah ikan yang dipasang di perairan Sendangbiru, Kabupaten Malang. Melalui kegiatan ini telah dilakukan alih teknologi pembuatan rumah ikan serta kegiatan pembukuan hasil tangkap, yang kelak diharapkan dapat bermanfaat bagi nelayan Sedangbiru pada khususnya dan perikanan Sendangbiru pada umumnya. Selain dari itu, diharapkan hasil dari kegiatan ini dapat diaplikasikan untuk kegiatan pemasangan rumah ikan di lokasi yang lain serta dapat digunakan untuk data dasar dalam pengelolaan sumberdaya ikan berkelanjutan di Sedangbiru. Rumah ikan sendiri berfungsi sebagai tempat pengasuhan bagi ikan (nursery ground) dan lokasi konsentrasi (fishing ground) ikan bagi kegiatan penangkapan.

\section{DAFTAR PUSTAKA}

Angga, n.d. Mengenal Rumpon | Fishmate.

Anonymous, 2014. Kabupaten Malang Dalam Angka Tahun 2013.

Harlyan, L.I., Sambah, A.B., Bintoro, G., 2015. Pemanfaatan Aplikasi GPS bagi Nelayan Sendangbiru Kabupaten Malang. Universitas Brawijaya, Malang.

Nurani, T.W., Wisudo, S.H., Wahyuningrum, P.I., Arhatin, R.E., 2014. Model Pengembangan Rumpon sebagai Alat Bantu dalam Pemanfaatan Sumber Daya Ikan Tuna secara Berkelanjutan. J. Ilmu Pertan. Indones. 19, 57-65.

Sari, J.L., Garnida, L.O., Kurniawan, M.K., Pangaribowo, D.R., Mirianah, M., 2014. Pengolahan Limbah Stryofoam dengan Agen Biologi Pseudomonads, in: Proceeding Competition Students Scientific Period 2014 Student Inventive. Senat Mahasiswa Universitas - Universitas Kristen Satya Wacana Salatiga.

Sartimbul, A., Iranawati, F., Guntur, 2015. Sosialisasi Daerah Penangkapan Ikan Berbasis Kesesuaian Ekologi secara Horizontal dan Vertikal. Universitas Brawijaya, Malang.

Simbolon, D., Jeujanan, B., Wiyono, E.., 2013. Efektivitas Pemanfaatan Rumpon dalam 
Operasi Penangkapan Ikan di Perairan Maluku Tenggara. J. Amanisal PSP Unpatti 2, 19-31.

Sudrajat, S.M.N.I., Rosyid, A., Bambang, A.N., 2014. Analisis Teknis dan Finansial Usaha Penangkapan Ikan Layur (Trichiurus sp) dengan Alat Tangkap Pancing Ulur (Handline) di Pelabuhan Perikanan Nusantara Palabuhan Sukabumi. J. Fish. Resour. Util. Manag. Technol. 3, 141-149. 